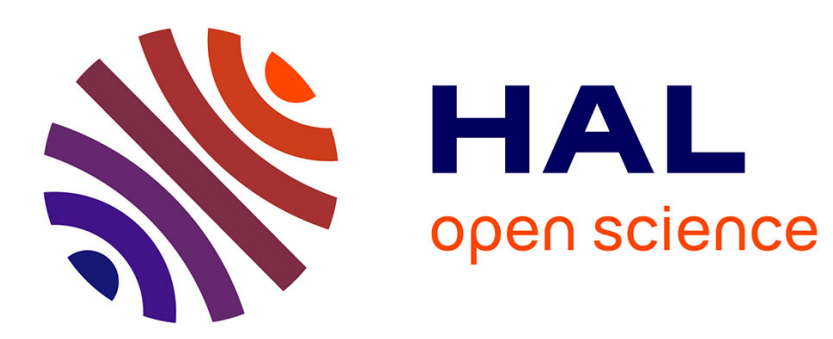

\title{
Argumentative reasoning and taxonomic analysis for the identification of medical errors
}

Mamadou Bilo Doumbouya, Bernard Kamsu-Foguem, Hugues Kenfack, Clovis Foguem

\section{> To cite this version:}

Mamadou Bilo Doumbouya, Bernard Kamsu-Foguem, Hugues Kenfack, Clovis Foguem. Argumentative reasoning and taxonomic analysis for the identification of medical errors. Engineering Applications of Artificial Intelligence, 2015, vol. 46, pp. 166-179. 10.1016/j.engappai.2015.08.009 . hal-01308900

\section{HAL Id: hal-01308900 \\ https://hal.science/hal-01308900}

Submitted on 28 Apr 2016

HAL is a multi-disciplinary open access archive for the deposit and dissemination of scientific research documents, whether they are published or not. The documents may come from teaching and research institutions in France or abroad, or from public or private research centers.
L'archive ouverte pluridisciplinaire HAL, est destinée au dépôt et à la diffusion de documents scientifiques de niveau recherche, publiés ou non, émanant des établissements d'enseignement et de recherche français ou étrangers, des laboratoires publics ou privés. 


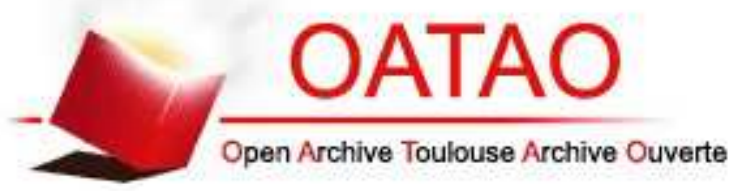

\section{Open Archive Toulouse Archive Ouverte (OATAO)}

OATAO is an open access repository that collects the work of Toulouse researchers and makes it freely available over the web where possible.

This is an author-deposited version published in: http://oatao.univ-toulouse.fr/ Eprints ID: 15541

To link to this article: DOI: $10.1016 /$ i.engappai.2015.08.009

http://dx.doi.org/10.1016/j.engappai.2015.08.009

\section{To cite this version:}

Bilo Doumbouya, Mamadou and Kamsu-Foguem, Bernard and Kenfack, Hugues and Foguem, Clovis Argumentative reasoning and taxonomic analysis for the identification of medical errors. (2015) Engineering Applications of Artificial Intelligence ( $\left.\mathrm{n}^{\circ} 46\right)$. pp. 166-179. ISSN $\underline{0952-}$ $\underline{1976}$ 


\title{
Argumentative reasoning and taxonomic analysis for the identification of medical errors
}

\author{
Mamadou Bilo Doumbouya $^{\mathrm{a}, \mathrm{b}, *}$, Bernard Kamsu-Foguem ${ }^{\mathrm{a}, * *}$, Hugues Kenfack ${ }^{\mathrm{b}}$, \\ Clovis Foguem ${ }^{\mathrm{C}}$ \\ a Université de Toulouse, Laboratoire de Génie de Production (LGP), EA 1905, ENIT-INPT, 47 Avenue d'Azereix, BP 1629, 65016 Tarbes Cedex, France \\ ${ }^{\mathrm{b}}$ Université de Toulouse, Faculté de droit, 2 rue du Doyen Gabriel Marty, 31042 Toulouse cedex 9, France \\ ${ }^{\mathrm{c}}$ Université de Bourgogne, Centre des Sciences du Goût et de l'Alimentation (CSGA), UMR 6265 CNRS, UMR 1324 INRA, 9 E Boulevard Jeanne d'Arc, \\ 21000 Dijon, France
}

Keywords:

Argumentation

Knowledge tracing

Taxonomy

Teleexpertise

Medical errors

Legal procedure

\begin{abstract}
A B S T R A C T
Telemedicine consists of the use of information and communication technologies (ICTs) in the practice of medicine. The massive digitalisation of the society is changing the behaviour of ordinary people even in medical sectors. The impact of digitisation is also having impacts on teleexpertise, where a medical professional can remotely ask some advices through the use of ICTs to provide treatment to a patient in critical conditions in remote environment. However, sometimes the outcome of such advice obtained remotely can lead to medical errors. In these situations, it is important to determine whether the causes of the errors could have been avoidable or not for the purposes of establishing the truth and assuring justice for the victims of medical errors. The proposed work fits this perspective with the objective to formalise elements of argumentation in collaborative medical organisations using telemedicine. In other words, a technique that extends the Dung's argumentation framework in order to bring out the errors committed following a remote medical procedure has been proposed. The proposed technique is underpinned by graphical reasoning. The reasoning is represented through a directed graph in which the extended nodes specify the arguments with their source(s) and the identification of errors is done according to the Makeham's and Tempos taxonomies. To illustrate the functioning of the proposed technique or solution, an example of the practice of teleexpertise (between two French hospitals) that leads to litigation is presented.
\end{abstract}

\section{Introduction}

In an increasingly digital society, there is a shift in the ways of designing efficient health care system and health management information system. Thus, health professionals and patients must prepare themselves to take advantage of established and enhanced healthcare processes that improve the quality of the service delivered. This is particularly important given the amount of scientific and practical evidence that the digital technologies and their numerous applications have significantly improved performance in many other domains and gradually doing the same in the healthcare sector. The opportunities being generated by these emerging ICTs must not be missed.

The French law on hospitals, patients, healthcare and local areas (HPST) proposes a prescriptive framework for the promotion

* Corresponding author at: Université de Toulouse, Laboratoire de Génie de Production (LGP), EA 1905, ENIT-INPT, 47 Avenue d'Azereix, BP 1629, 65016 Tarbes Cedex, France.

** Corresponding author. Tel.: +336243023 37; Fax: + 33562442708 .

E-mail addresses: mdoumbou@enit.fr (M.B. Doumbouya), bernard.kamsu-foguem@enit.fr (B. Kamsu-Foguem). and protection of equitable access to health care (http://www. legifrance.gouv.fr/). In particular, Article L6316-1 of the law contains provisions concerning the services of the telemedicine: telemedicine is a form of remote medical practice using ICTs. It enables communication among health professionals (which must include at least a qualified medical professional) or with their patients and, where appropriate, of other professionals involved in the provision of care to the patient. It provides the means to establish: a diagnosis, of a risky or very vulnerable patient, to ensure, monitoring for preventive purposes or post-treatment surveillance, to ask for specialised advice, to prepare a therapeutic decision, to prescribe products, to prescribe or to perform the services or acts or to conduct monitoring of patient conditions. In fact, the telemedicine facilitates the efficient provision of healthcare services. In particular, telemedicine bridges the challenges often encountered across different service levels including primary care, regional and national care services, coordination between health care institutions, mobile medicine, medical and medical-social actors, promotion of regional or virtual clustering, new modalities for collaboration among medical partner organisations (Kamsu-Foguem et al., 2015a; Kamsu-Foguem et al., 2015b; Sene et al., 2015; Kamsu-Foguem and Foguem, 2014a; 
Kamsu-Foguem and Foguem, 2014b; Doumbouya et al., 2014; Kamsu-Foguem, 2014c, Kamsu-Foguem, 2014d). This contributes to improve regional attractiveness and valuation of certain health professions and optimal operating efficiency, and convergence plans towards strategic scheduling. The procedures of telemedicine do not fundamentally undermine the essential principle of a personal practice of medicine, each physician remaining responsible for his or her own actions or inactions. In the case of a remote diagnosis, the requesting physician who uses (through a computer network) the services of an expert colleague has no liability for the acts or omissions of this external collaborator. The diagnosis made by the expert is the entire responsibility of this required physician. However, the liability of the requesting physician might be initiated by the patient if it were demonstrated that this doctor made errors or omissions in the content of the information communicated to the expert. If the requesting physician participates in the elaboration of a diagnosis, his liability might be mentioned in this regard and in such circumstances, the responsibility of both doctors might be considered.

Teleexpertise is one of the five important practices of telemedicine (Doumbouya et al., 2015a), which is sometimes used to save life in critical care and emergency situations. It allows remote collaborations between several medical professionals and optimises the management of patient with complex illness. Furthermore, the emergence and the growth of the Internet and digital technologies offer universal access to information, allowing a larger involvement of patients by encouraging the establishment of a more open dialogue with physician. More importantly, the introduction and adoption of these emerging digital technologies provide opportunities for victims of medical errors, the understanding of the causes of errors and their impact on diagnosis or therapy. It is important to note that medical error is not the only requirement for a medical review and hence litigation. For example a litigation can be occurred when a patient is not satisfied of his treatment. The patient or his legal representatives may apply to a judicial procedure or may refer to the Regional Commissions for Conciliation and Compensation for Medical Accidents (CRCI). The CRCI will cover the cost of required medical expertise and based on the seriousness of the potential prejudice, the procedure will be the conciliation or the amicable or mutual agreement. So when this situation occurs, it is important to facilitate the work of legal experts by offering them a way to easily collect all the data they need for the expertise. It is against this backdrop that this study is developed i.e. providing a tool to legal experts to help them in their practice when a litigation occurs.

This paper is divided into 7 sections. Section 1 introduces the research context while the rational is discussed in Section 2. To facilitate understanding and also ground this research, a state-ofthe-art review of common medical errors is conducted in Section 3. Based on the review in Section 3, research methods adopted are discussed in Section 4. In Section 5, real-life case study illustrating the challenges faced teleexpertise and proposed solutions has been examined. Section 6 is about a discussion of the major issues in this study. The study concludes by a way of summary in Section 7 .

\section{Motivation and objective}

Nowadays with the rising of technological and electronic devices, the practice of telemedicine is in the process of taking a considerable place in the medical community. But we need to be aware that this practice sometimes raises complex medico-legal issues. So to clarify the legal responsibilities of each participant, we must have an information modelling approach that allows the judicial system to get a valuable insight into understanding the circumstances of the considered medical accidents. The quality of forensic evidence must be examined in its entirety, from the beginning of the procedure with detailed information according to the applicable procedural rules. The diverse participants of the judicial system must be supported by the development of consistent tools allowing to provide and distinguish arguments according to their weight or importance of evidence and to highlight the more credible elements of the analysis, as well as those which are of less relevance. Telemedicine has the obligation to deliver services with associated information and reasoning that are based on documented, conclusive and convincing evidence. It is thus expected that telemedicine must implement health information management modules that ensure traceability of coherent and reliable evidences to enable enlightened and well-founded decisions of the judicial system. Consequently, the aim of this study is to provide an information system architecture that will allow or help key judicial or legal actors (e.g. judges and prosecutors) to draw a clear and assessable representation of the examined litigious medical case for evaluating relative responsibilities. To achieve the aim of this study, a combination of the Dung's argumentation framework and semantic modelling principles was employed. Dung's argumentation framework is based on mathematical foundations that guarantee formal reasoning. The framework models arguments with graphs such that nodes represent arguments and arrows represent the attack relation. Semantic modelling offers taxonomic analysis of medical errors. Our work is aimed at producing added value with the integration of available sources of arguments proposed by medical professionals directly in the node of the graph of attack to consolidate the decision making process and medical collaboration through the telemedicine.

\section{State of the art of medical errors in healthcare systems}

\subsection{Diagnosis errors}

Since the 1970s, scientists study clinical decision-making in order to improve its processes. Clinical decision-making is also called clinical reasoning, clinical judgement, clinical inference or diagnostic reasoning (Ge et al., 2012). Scientific context, clinical decision-making can be categorised into two modes (Ge et al., 2012):

- Deductive mode: When decisions are based on theoretical knowledge of diseases and the mechanisms of different treatments.

- Empirical mode: When decisions are based on past experiences.

Different techniques have been used in clinical decision-making process. Some common techniques are decision trees, Markov models, and simulation. Clinical reasoning is an important contributor to the quality of healthcare, but to achieve this quality of healthcare, the provided decisions in the clinical reasoning have to be safe. Some works such as Goal Structuring Notation (GSN) (Ge et al., 2012) have been made in this way. It enhances communication between medical professionals and is more suitable and convenient for analysis of medical errors.

Lawson and Daniel (2011) propose a work in which they attempted to reduce and even eliminate diagnosis errors. The diagnosis errors encountered in healthcare care systems are generally caused by cognitive errors. These errors represent $80 \%$ of diagnosis errors (Lawson and Daniel, 2011). To facilitate understanding, these errors are illustrated in Fig. 1 using the Makeham's taxonomy. This taxonomy is divided into two main categories of errors:

- Process errors: This category covers care system errors coordination, errors due to complementary examinations such as 


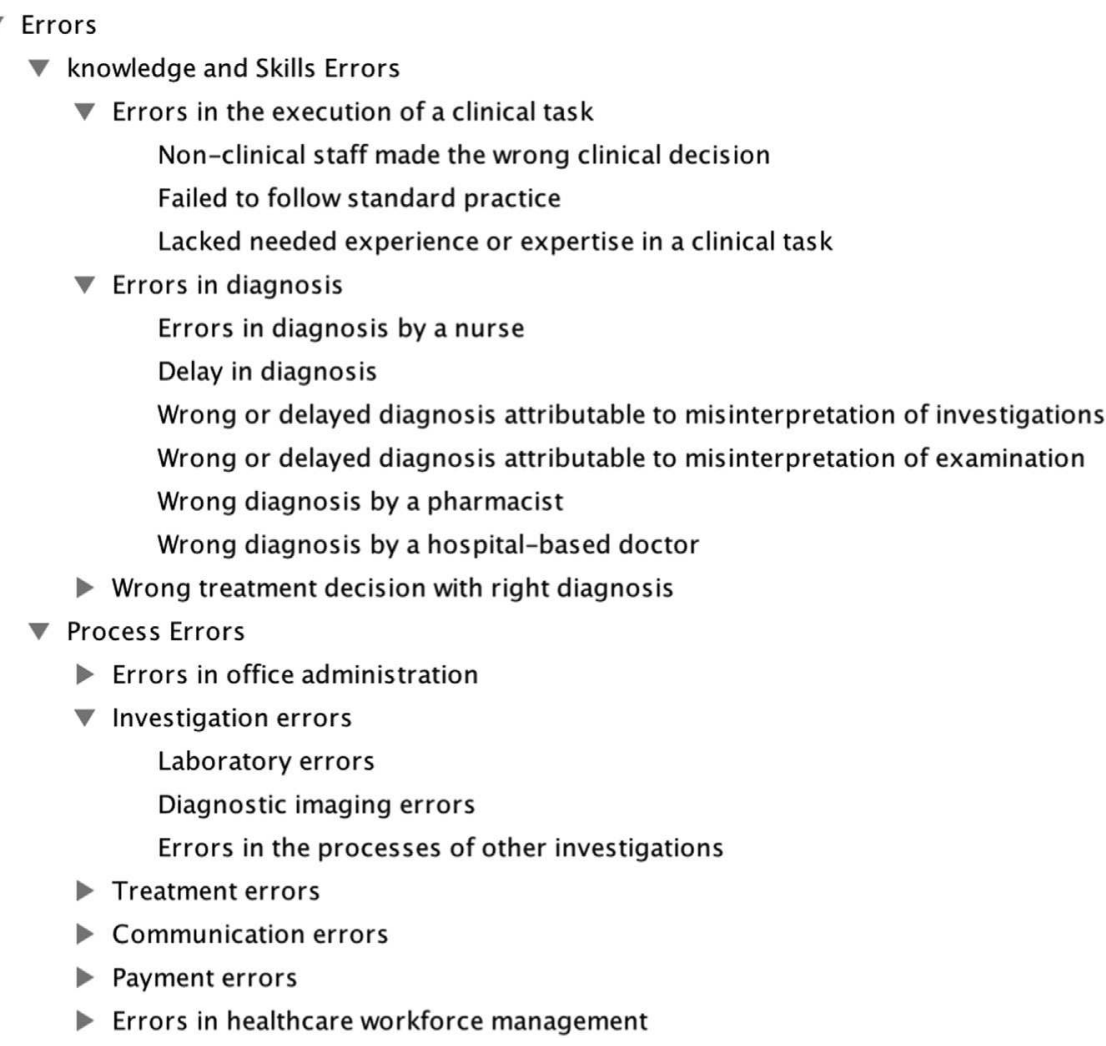

Fig. 1. Makeham's taxonomy representing the first three levels of taxonomy of errors.

prescription, realisation and results' management, errors related to medications, errors related to non-medications and communication problems.

- Knowledge and skills errors: This category is composed of three main concepts, namely: (1) errors in the execution of clinical tasks, (2) errors in diagnosis, (3) wrong treatment decision with right diagnosis.

Another area where medical errors have been investigated is in e-health cardiology (Gortzis and Nikiforidis, 2008). In e-health cardiology two kinds of knowledge processes are supported (Gortzis and Nikiforidis, 2008):

- Knowledge tracing: This demonstrates how a system executes and produces knowledge.

- Knowledge cataloguing: This classifies the knowledge that already exists within the information system.

Based on these knowledge processes, Gortzis and Nikiforidis (2008) proposed a system, for minimising errors in healthcare systems (e.g. e-health cardiology environment). Their approach is quite similar to teleexpertise since it allows collaboration between medical professionals. The authors of Gortzis and Nikiforidis (2008) achieved their goal by considering knowledge tracing process and knowledge cataloguing process. With regards to the knowledge tracing process that shows how the system executes and produces knowledge, they demonstrated how the collected data are accepted or rejected. The collected data consists of a set of variables provided by the patient via portable devices. Each variable is associated with an upper threshold $\left(V_{U P}\right)$ and lower threshold $\left(V_{L O}\right)$ (see Eq. (1)). The developed software performs a first filter or screening by discarding data that are noisy and unrelated to the patient and then data supposed to be valid are stored in the knowledge base. The system can response to some

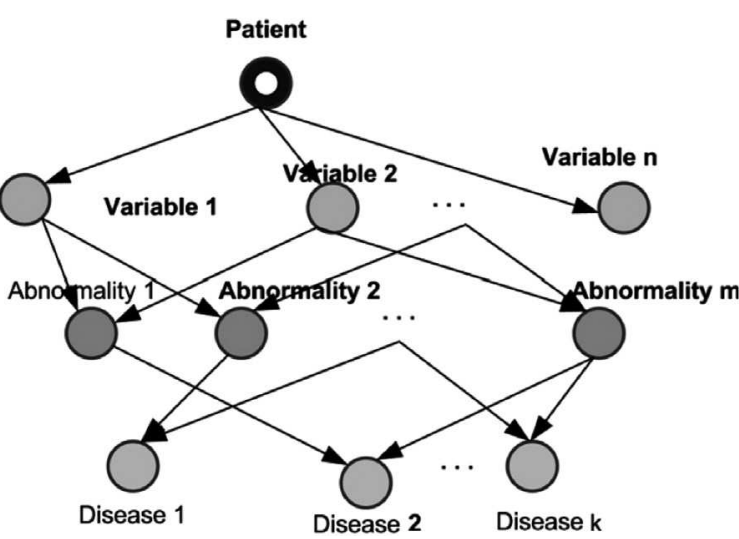

Fig. 2. Knowledge graph (Gortzis and Nikiforidis, 2008).

queries and gives as output, the type of disease from which the patient suffers. However, this first result has to be validated by an expert. Each node of the underlying knowledge graph (Gortzis and Nikiforidis, 2008) computes the incoming data, or a request to determine the right path which leads to the corresponding disease as shown in Fig. 2. However, the reasoning is hidden from the users, arguments are not visible and the sources of arguments are not provided.

With regards to the second process i.e. the knowledge cataloguing, it is a procedure that allows the classification of knowledge that already exists within the information system. In this process three knowledge catalogues are structured (Gortzis and Nikiforidis, 2008), namely (i) patient in life, (ii) patient in time, (iii) patient in action. So when a medical professional provides new information, it is catalogued as patient in life. Information for patient in time catalogue is obtained by the following equation 
called Patient Current Equation PCE):

$P C E=\operatorname{mean}\left[\left(V_{U P}\right),\left(V_{L O}\right)\right] \pm S D$

where $S D$ designates the Standard Deviation.

The software agent computes this equation in order to provide information for the patient in time catalogue.

For the patient in action catalogue, the system makes a comparison of the received value according to the corresponding PCE (Gortzis and Nikiforidis, 2008). This will allow the system to identify the risk level. This approach is quite technical similar to the teleexpertise since it allows collaboration between medical professionals. However, the proposed knowledge cataloguing technique based on PCE (Gortzis and Nikiforidis, 2008) was not developed for telemedicine and does not consider the legal obligations related to the medical practice. Nonetheless, the authors Gortzis and Nikiforidis (2008) argued that the expert can discard some results if he judges them insufficient and irrelevant. The expert could be wrong by eliminating a result that should not have been discarded. Thus to remove any doubt regarding the remote medical practice, the expert should provide evidence that supports their decisions.

The work proposed by Elkin et al. (2013) also deals with medical errors handling. In fact, Elkin et al. describe an ontology (called usability-error ontology) for handling medical errors in clinical contexts. The ontology can be employed to help to improve the patients' treatment outcomes while ensuring the interoperability of the medical systems. In their ontology the top level is divided into two levels, namely (i) Cognitive Errors, (ii) Non-Cognitive Errors, which is a good classification since several medical errors are caused by human being. This work is interesting since it reveals the Usability Errors in the Health Information Technology (HIT) or its interaction with users. However the study of Elkin et al. (2013) does not explicitly discuss how medical professionals can collaborate, a very important aspect in telemedicine.

\subsection{Legal procedure}

In France, only the victim of a medical error or his/her legal representatives (in the event of incapacity or minor) or his/her beneficiaries (in the event of death) have the responsibility to provide any evidence of a medical fault. The procedure followed by the victim is described in Fig. 3.

First of all there must be a preliminary technical investigation that mainly consists of checking the supporting documents such as the Personal Medical Record of the victim (complainant). It is crucial to get this document before the meeting with the expert (Rougé, 2012).

A medical accident is an unexpected adverse event that results from undertaking a medical activity of care, prevention or diagnosis, whether in a healthcare facility or medical office. In case the accident could have been prevented, the healthcare professionals (a doctor or a health facility for example) in charge can be subjected to a civil and/or penal liability. Alternatively, it may be a case of medical complications and/or side effects of medication, both of which are not dependent on medical professionals. This is often called therapeutic contingency. The accident can cause damage giving rise to compensation. The right to claim the compensation depends whether it related to a fault committed by the medical team or one of them or a therapeutic contingency. In case of fault it is for the health actor to repair the damage, while the right to reparation (compensation) is available on the basis of a professional activity. This damage is covered by professional civil liability insurance of the health actor. In case of therapeutic contingency, the National Office will pay the compensation out of a national solidarity scheme for the Indemnification of Medical Accidents, Iatrogenic and Nosocomial Infections (ONIAM).

\section{Research methods}

In this section the methods used to achieve the aim of this study will be examined. As previously discussed, the goal of this study is to provide a system which allows medical professionals participating in a teleexpertise process to list the sources that support their arguments and beliefs. This will help the medical professionals in case of legal procedure in the step of forensic examination, investigating judge or expertise mentioned in Fig. 3 where expert documents are needed. As a key step in the method, the Dung's argumentation framework was extended by incorporating a supplementary reasoning element called source in the formal graphical representation of a node's structure.

The proposed framework provides a possibility to automatically generate a report for the experts and contains some useful information at the litigation stage. This pertains to a teleexpertise process that was/is the subject of any complaint or that has been challenged. The contribution of this study is the proposed system which uses a two-step approach to attain the intended goal. Firstly, the Dung's argumentation system is used to retrieve the potential acceptable decisions that might have been used in the argumentative process of tele-expertise through a component called argumentative logic. The theory and details of argumentative logic have been covered in Doumbouya et al., 2015a,b, hence this effort will not be duplicated here. Secondly, the acceptable decisions are compared with those mentioned in the medical report. This comparison provides an opportunity to analyse and present various options with conflicting views and to generate an expert report. The two contributions have been captured in the system architecture presented in Fig. 4.

The details of the architecture will be explained in the ensuing sections. The sources of the facts are derived in particular from an important component of the proposed framework that is the knowledge base. This knowledge base includes Personal Medical Record (PMR) and Taxonomy of Medical concepts and it is connected to the Reasoning and Decision Making processes.

- Personal Medical Record (PMR) that describes the Electronic Patient Files shared among members of the medical professions;

- Taxonomy of Medical concepts that describes a group of controlled vocabulary terms structured into a hierarchical organisation;

- Reasoning and Decision Making, which provide procedures to build a credible means of tracing information and analyses circumstances in terms of errors search facilities.

\subsection{Personal Medical Record (PMR)}

With the PMR including traceable data, it will be very easy to provide the proof of errors instead of checking paper documents given that the medical documents to be provided must be ordered chronologically (Rougé, 2012). However, the physician in charge of the patient must obtain his/her express and informed consent about how his/her data will be used and who will have access to these data. Thus the elements in the Personal Medical Record are as follows:

- Medical professionals intervening in the act;

- Act performing report;

- The acts;

- Achieved medications;

- Medical professionals identity; 


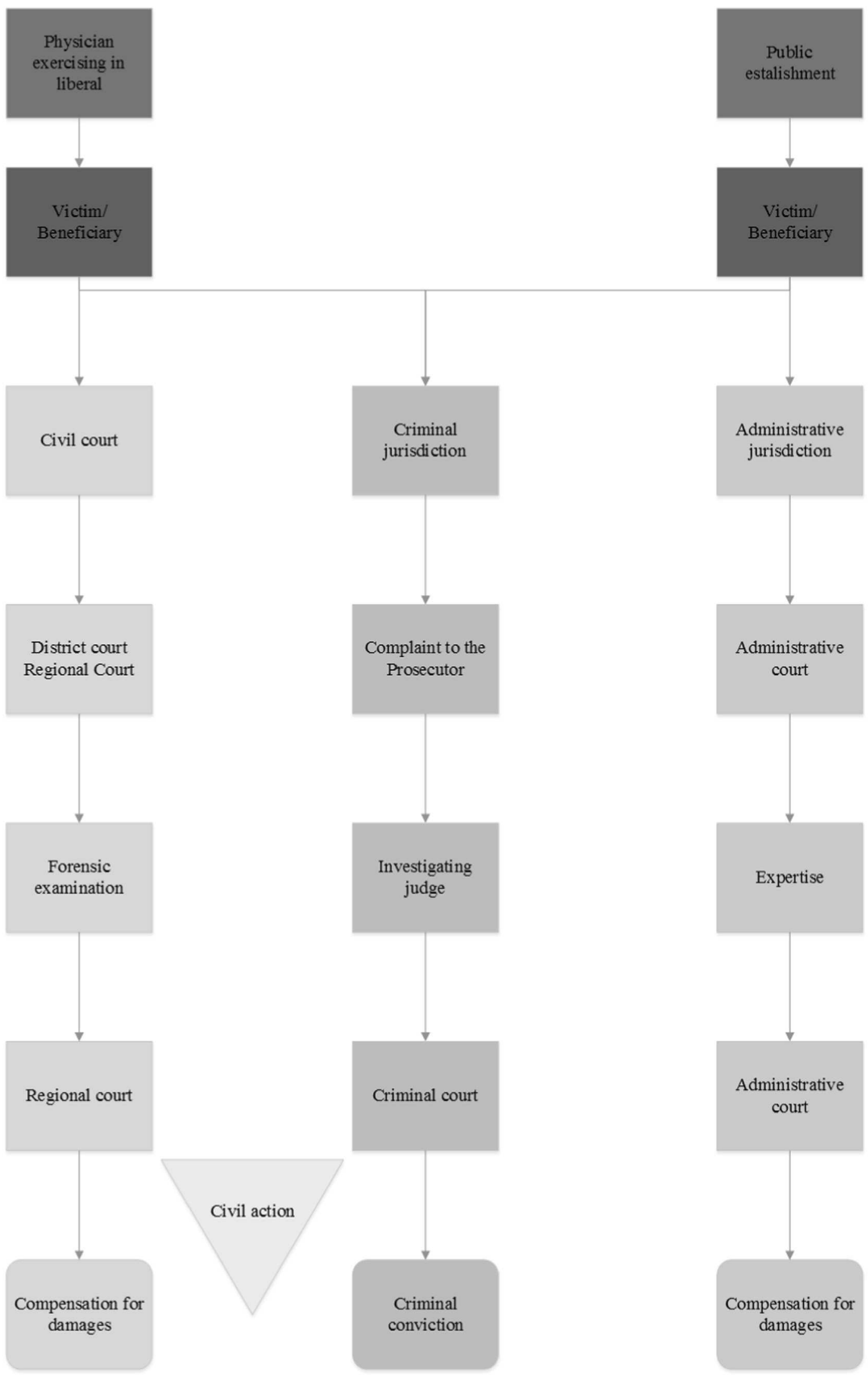

Fig. 3. Legal procedure in France. 


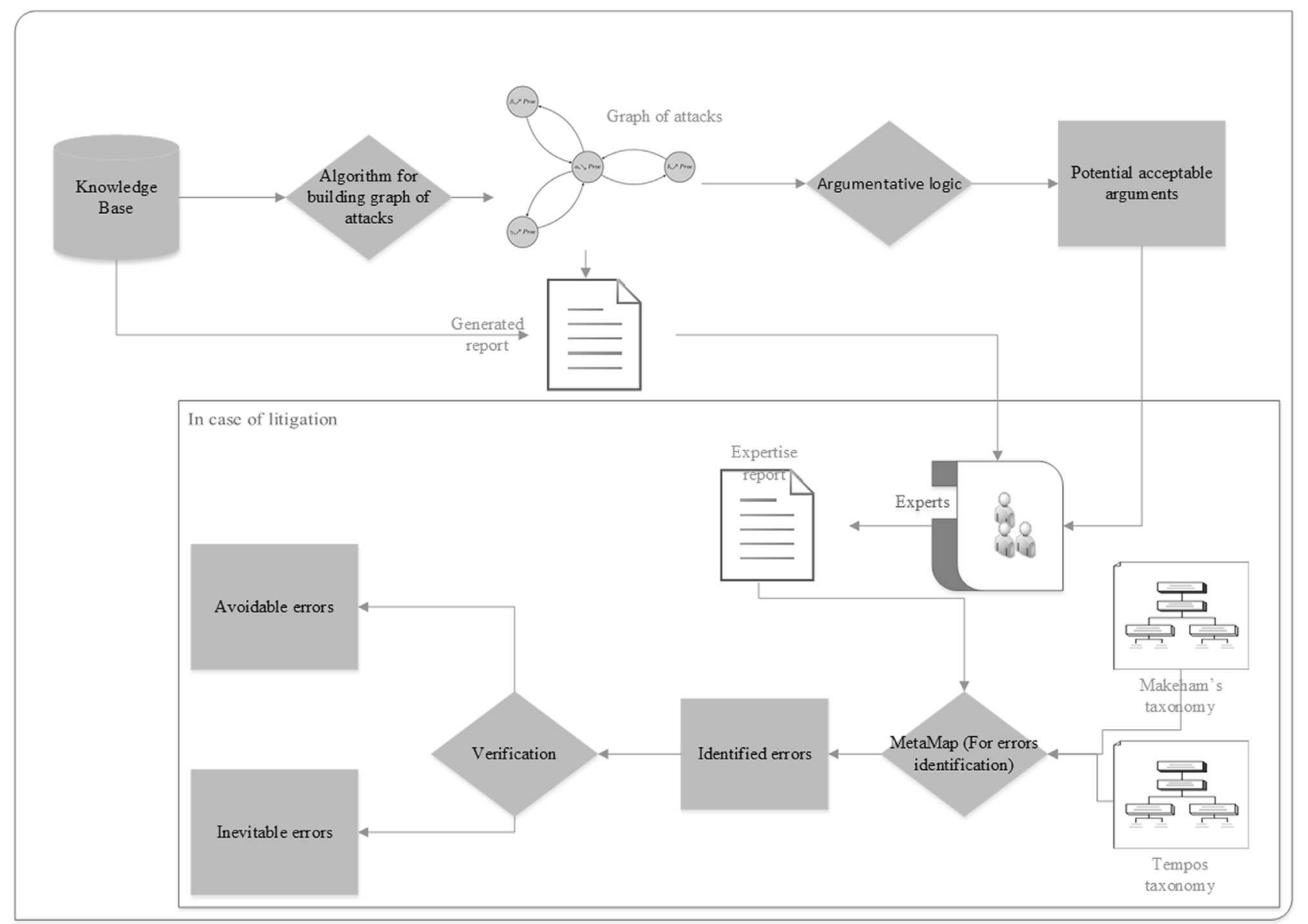

Fig. 4. Proposed architecture.

- Date and hour of the act;

- Technical incidents occurred in the act;

- Each participant (requesting, required physician) must record pertinent information concerning his or her intervention from the patient. The pertinent information could be the sources that sustain their decisions.

\subsection{The responsibilities of medical professionals in teleexpertise}

Given the collaborative underpinning of teleexpertise, this section will dwell on the responsibilities of each stakeholder participating in the collaborative process. The teleexpertise is a practice of telemedicine, which allows/facilitates collaboration between multidisciplinary medical professionals. Given that tele-expertise is underpinned by collaboration, the main challenge has been/is to determine who is responsible for what in case of diagnosis errors. In case of teleexpertise, the requesting physician is responsible of the collected and tele-transmitted information, the information delivered to a patient and the final decision taken. However, when the diagnosis error constitutes a common fault, the legal regime applicable is the joint and several liability of the requesting physician and the required physician (http://www.sante.gouv.fr/IMG/ pdf/Telemedecine_et_responsabilites_juridiques_engagees.pdf).

\subsection{Node's structure in the graphic representation of argumentations}

Given that we are working with the notion of structural argumentation (Besnard et al., 2014), it is then important to describe the internal structure of elements that constitute the nodes in the

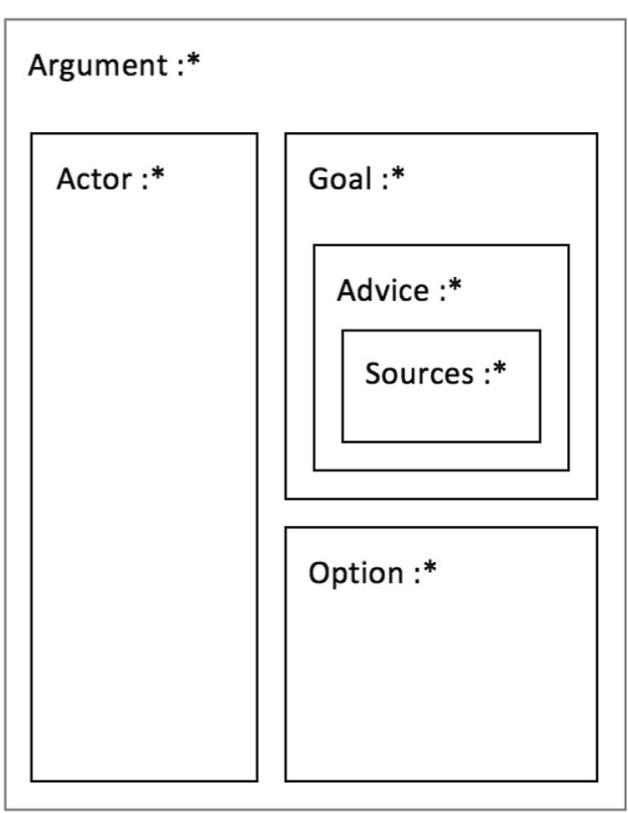

Fig. 5. Node representation.

graph of attacks. Fig. 5 shows the internal structure of a node in the graph of attacks represented in a conceptual graph form. It is important to note that Fig. 5 is one of our contributions to this study. In conceptual graphs (Chein and Mugnier, 2009; Sowa, 1984; Sowa, 2000), this kind of node is called a nested node in 
which the reasoning with projection operation can be made by a recursive procedure to find the sets of collectively acceptable arguments. When the data are extracted from the knowledge base, this node is fed as follow:

- Argument: Which can be represented by a number to distinguish between the arguments of the different stakeholders.

- Actor: It characterises the medical professional participating in the concerned act of teleexpertise.

- Goal: It characterises the target to be attained by the medical professional. The goal is broken into:

- Advice: Which is the decision supported by the medical professional

- Sources: It represents where the concerned medical professional took or collected certain key information in order to justify his decision. The sources deliver necessary elements to strengthen the reliability of the arguments on which the medical decision is effectively based. This is to allow the collaborative health institutions to work more efficiently in improving the quality of patient's care to satisfy the increasing administrative and legal requirements of professional medical practices;

- Option: It represents the choice that the medical professional can take when he/she is undertaking a medical action. For our case study (Section 5), one has two main options (Chalumeau et al., 2008): (i) maximisation of the procedure ( $T$ Proc), (ii) minimisation of the procedure ( $\searrow$ Proc $)$.

\subsection{The proposed system architecture}

Fig. 4, illustrates the architecture, which is mainly based on Artificial Intelligence tools such as taxonomies and argumentation (argumentative logic).

Fig. 4 is composed of two main parts. The first part is to generate a medical report when a medical error has occurred, or is suspected to have occurred, and the second part uses the generated medical report to trigger another report called expert report, which will be used to determine the nature (whether they are at fault or not) and scope of the medical errors evidenced by report:

- Generation of the medical report: In this part there is an algorithm that extracts information from the knowledge base to build the graph of attacks. In essence, the formal underpinning principle of algorithms for generating a graph of attacking arguments is a network reasoning model (Modgil and Caminada, 2009) in which the justification state of arguments (nodes) is determined by propagating the attacks of the connected nodes in order to derive a set of arguments which are "collectively acceptable" (Baroni and Giacomin, 2009) (i.e. they are able to survive together and to withstand the external attacks). The work achieved by Doumbouya et al. (2015a) explains deeply how the argumentation logic is used in medical context. In this work, the argumentation logic is executed over the resulted graph of attacks in order to retrieve the arguments that were acceptable in the process of teleexpertise that led to litigation.

- Generation of the expert report: When the medical report is generated, the legal experts composed of medical professional use this one combined to final decisions to build the expert report. It is important to note that in France, the legal experts are nominated by the government (http://www.legifrance.gouv. fr/affichTexte.do). The national list of legal experts serves as reference for appointing expert medical professionals in a context of the litigation purposes. The medical professionals (categorised by discipline) are accredited to be included on this list on the basis of their respective qualifications and practical experience. Normally, in the framework of a legal dispute, the expert report contains five chapters:

1. The statement of facts, taking into account both stories and medical documents;

2. The in-depth analysis of the case file based on medical records;

3. The presentation of medical evidence in support of a patient's claim;

4. The discussion to determine whether such constitutes a therapeutic contingency or a faulty medical error or not by providing some specific arguments;

5. The conclusion that specifies if the current health condition of the patient with physical and psychological damage described is in proven direct relation to the error committed by the health actor.

In order to avoid heavy cost of storing files after a process of teleexpertise, we propose to build automatically medical reports when needed. Required data are extracted from the knowledge base to build the graph of attacks. Then argumentation helps in this way to retrieve the medical professionals' advices that have been accepted in the act of teleexpertise leading to suspected or real errors. When the previous accepted advices are known, the legal experts use these ones and the medical report automatically generated to build another report that we call "expert report". This last report will be used in the second part of Fig. 4 for identifying the errors that occurred. Therefore, in the first phase, the generated report (called medical report) specifies the identified arguments associated to the considered medical decision-making; while in the second phase the generated report (called expert report) shows the potential identified medical errors.

In this architecture the data are retrieved from a remote knowledge base. This action is performed by an algorithm whose output is the graph of attacks as illustrated by Fig. 7. Given that all information are stored in XML (http://www.w3.org/XML/) format since we use CoGui software (http://www.lirmm.fr/cogui/) for concepts modelling, then it is easier to produce a human readable report that will be given to the experts for courts' expertise in case of litigation. This report will be fundamental for courts' expert in order to identify the errors that led to litigation. The experts focus on this report and the computed decisions provided by the argumentative logic (Doumbouya et al., 2015a) for producing their own report that will be used by the courts. In this later report are shown the different errors that led to the litigation. Then by taking into consideration the Makeham's taxonomy (Makeham et al., 2002), the Tempos taxonomy (Amalberti and Brami, 2012) (see Fig. 6) and the MetaMap software since it permits to make classification (Aronson and Lang, 2010) and applied them to the experts' report, it would be possible to identify the potential errors according to an international taxonomy and verify if these errors are preventable or not. The Tempos taxonomy has been introduced in safe and efficient medicine in order to incorporate in it the notion of time management since the medical institutions present a lack of this important notion (Amalberti and Brami, 2012). So in this work the Tempos taxonomy accompanied with the Makeham's taxonomy will be useful for clarifying the medical errors in order to determine if they could be avoided or not.

All the process depicted in Fig. 4 is executed if and only if there were potential medical errors in a process of teleexpertise. The output of the argumentation logic is a list of arguments that are potentially acceptable and built from medical information stored in the knowledge base as indicated in Table 1. Hence, one can clearly highlight the alternative decisions initially discarded and confront them with the accepted ones described in the medical report. 

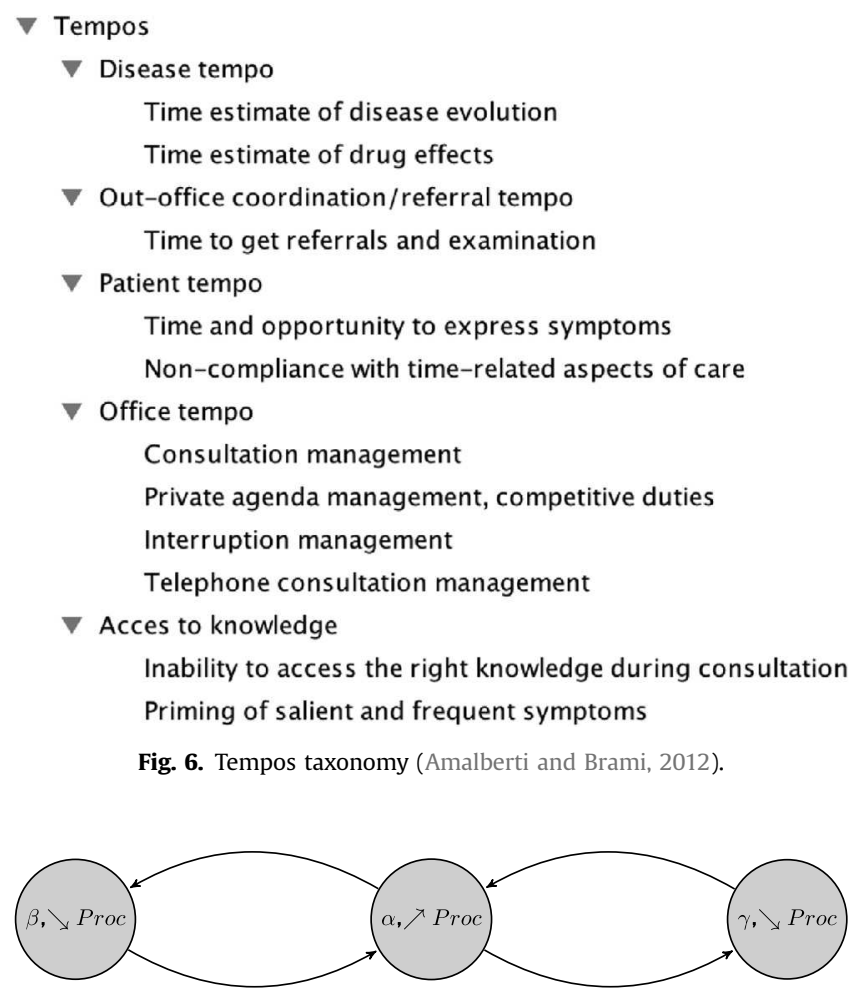

Fig. 7. Graph of attacks.

The proposed approach is well described in the case study section. In fact in this section we explain step by step the main purpose of each component of the architecture.

\section{Analysis of results with case study}

\subsection{Case study}

This section is divided into two sub-sections. The first section illustrates a scenario of teleexpertise and the second shows the decision made by the courts (Tribunal administratif de grenoble, 2010). It is a real case study of teleexpertise between Sallanches hospital centre and the University hospital centre of Grenoble, both located in France.

\subsubsection{Scenario of teleexpertise}

A patient is admitted in a Hospital Centre due to a head injury sustained from a paragliding accident. A computed tomography (CT) of human brain was performed, and the results did not reveal any abnormalities. Hence, the patient was allowed to leave the hospital a few days later. A month later, this patient was hospitalised again due to an unusual headache and vomiting. The condition did not improve even after patient was administered some analgesics. A CT scan was performed and a teleexpertise was requested to neurosurgery department of a University Hospital Centre with video transmission of images resulting from an examination that shows a bilateral frontalparietal subdural haematoma. This University Hospital Centre stated that he did not have available space and the clinical condition of the patient permits a delay to perform a drainage operation of haematoma, which had to be postponed due to the risk related to aspirin consumption. The next day, the patient's clinical condition has worsened. The neurosurgery service of the University Hospital Centre did not change its stance on the action to be taken. The patient went into a coma and was transferred to another specialised medical centre where he died. 
This scenario of teleexpertise is based on a real case that has allowed collaboration between two hospitals, namely the hospital centre of Sallanches and the university hospital centre of Grenoble. This scenario describes the main communications between these two hospitals that have been previously achieved. This is traced in the PMR and will be used to extract the argumentation according to the fields of Table 1.

The teleexpertise contains guidelines for the informed, responsible and collective practice of medicine in a collaborative practice involving multidisciplinary staff. In this respect, the article R.4127-64 of the French Code of Public Health specifies "when several doctors collaborate in the examination or treatment of a patient, they should keep each other informed; each practitioner assumes its personal responsibilities and ensure the information of the patient." In this regard, each image interpretation request must be the subject of a written report, signed by the required physician and sent immediately or within the shortest possible time to the requested physician with a view to integrate it into the PMR. Both physicians can, by telephone or by videoconference, share their opinions on the interpretation of medical images and the applicable mechanisms for the diagnostic and therapeutic management of the patient. The practitioners must respect their collaborative agreement and the procedural rules developed for telemedicine acts, particularly those concerning the traceability requirement. In the opinion of the court, as hospitals did not follow established teleexpertise procedures and without the explicit mention in the patient's documentation, the faulty nature of acts is identified since there is at least one error by omission. The Dung's argumentation framework is included in the structured Argumentation Frameworks that is an extension in which the strength of an argument can be expressed in terms of its internal structure with possible valuation (Bench-Capon, 2003). Using these frameworks it is possible to assess a risk level or evaluate the acceptable arguments with a level of severity.

Modelling information available in structured arguments: The arguments are modelled according to the data available in the knowledge base. We suppose that these data are instantiated in the knowledge base as shown in Table 1 .

The university hospital has two arguments. These two arguments represent chronologically the different decisions of the University Hospital. Even if they are based on the same source they are chronologically different (differentiated by the number given in the first column in Table 1). In fact, in our model an argument can be supported by one or more sources and also one source can justify one or more arguments (Fig. 5). In addition, the intrinsically dialectical characteristic of argumentation obviously offers itself to the formulation of argument games (Modgil and Caminada, 2009) in which an initiator starts with an original argument to be tested, and then a challenger and the initiator sequentially attack each other's arguments. It was observed that the argument game approach dovetails well with our understanding of reasoning as an incremental process in arguments exchange and evaluation for knowledge acquisition. As a result, in our model the notion of time is taken into consideration, but this one is implicitly modelled.

Graph of attacks representation: The data are extracted from the knowledge base by an algorithm to build the graph of attacks as presented in Fig. 7.

The used principle of the algorithm for building the graph of attacks is based on the conceptual graphs formalism. In this formalism the main reasoning procedure relies on the projection operation (Baget and Mugnier, 2002). This operation exploits the semantic comparison between nodes of the graphs according the underlying ontological representation (Kamsu-Foguem et al., 2014e, Kamsu-Foguem et al., 2014f, Kamsu-Foguem et al., 2014g, Kamsu-Foguem et al., 2013, Kamsu-Foguem, 2012). An attack relation exists between two nodes of the graphs if and only if there is no projection operation from the option of the first node into the option second one (Bourguet, 2011).

After the graph of attacks is computed, the argumentative logic is applied to established acceptable decisions. So by following step by step the work achieved in Doumbouya et al. (2015a), in this case all the arguments (i.e $\alpha, \beta$ and $\gamma$ ) are credulously acceptable, even the patient did not receive any treatment except the aspirin. Generally, it is the requesting physician that validates the advices provided by the different medical professionals when all the advices are collected and the argumentative logic returns the acceptable arguments to him (Doumbouya et al., 2015a). After the validation, only the final decision of the requesting physician will appear in the medical report, the rest of the advices (if it remains) will be stored in the PMR. The sources are just for supporting their argumentation. These sources also represent an important justification if litigation occurs.

The output of the argumentative logic is the arguments that are susceptible to be accepted under a given semantics (Dung, 1995) (here the preferred semantics). In the process of teleexpertise when these acceptable arguments are computed by the argumentative logic, they are returned to the requesting physician (Doumbouya et al., 2015a). From then on the basis of some parameters, he takes the final decisions by approving some the returned advices and discarding the others. However, the argumentative logic makes it possible to retrieve these acceptable arguments in order to compare them with the ones mentioned in the medical report (i.e. the advices approved by the requesting physician). The evaluation of the acceptable arguments is consistent in the way that the argumentative logic is based on fundamental mathematical tools (definitions, properties, theorems, which are correctly proved) rooted in Dung's argumentation.

The outputs of the argumentation logic are the arguments (i.e. advices) that are potentially acceptable. The data are stored in a remote database as shown in Table 1 . So after building the knowledge base and extracting these data and executing the algorithm to build the graph of attacks, the argumentation logic typically retrieves the acceptable arguments. Concerning reasoning procedures, the underlying semantics of abstract argumentation frameworks have common properties with some concrete logic formalisms in linked contexts (e.g. logic programs with negation as failure and Reiter's default logic) (Dung, 1995). This implies that it is possible to validate the models produced by argumentation logic with other formalisations through suitable mappings. In addition, the practical pertinence of the generated arguments and suggested conclusions can be controlled and validated with regards to medical expertise and legal principles.

\subsubsection{Guidelines and treatment protocols}

In French hospitals, medical professionals must follow the national guidelines included in the Therapeutic Guide (Perlemuter and Perlemuter, 2014) provided to them to guarantee the proper functioning of medical services for providing the best care to patients. This therapeutic guide specifies the procedure to be followed by practitioners to deal with diverse clinical situations in compliance with the standardised recommendations. Particularly, the Neurosurgical Management of traumatic brain injury guideline commonly discussed in scientific literature (Bullock et al., 2006) recommends a rapid surgical treatment of acute subdural haematomas in the case of a subdural haematoma thickness greater than $10 \mathrm{~mm}$, or a Midline shift greater than $5 \mathrm{~mm}$ visible on the CT scan. The national consortium of neurosurgeons abides by this international guideline and makes recommendation and protocols used by the two hospitals in this case study. The medical professionals also refer to the ICD (International Classification of diseases) (http://www.who.int/classifications/icd/en/). The PMR is stored under an authorised system hosting personal health data 
for example. The diagnosis and treatment are documented through the different fields composing the PMR (refer Section 4.1). By the establishment of the PMR, it will be very easy for medical professionals to document the cares and at the same time allow or facilitate a better collaboration between them since the PMR is an online document accessible in real time via secure means. In fact, the argumentative logic is a kind of decision-support system, which will facilitate the retrieval of the acceptable arguments in the disputed process of teleexpertise. The proposed system is designed especially for medical expertise operations, and it is dedicated to serve the logical pertinence of the medical professionals' arguments and the experts' conclusions. The proficiency of medical experts is very useful for identifying possible medical errors or contingencies with regards to a legal dispute. Our proposed approach can be linked to the existing medical infrastructure in order to retrieve information about patients, medical professionals and diseases. Its main aim is to provide a tool for legal experts for building quickly an expert report. This tool can contribute to the Healthcare Safety and Security by offering means to deeply analyse the problem in case of legal dispute after a suspected healthcare-related incident.

\subsubsection{Expertise scenario}

As previously said when a litigation occurs a committee of experts is organised in order to identify the problems (errors) that lead to the ligation. In France, according to the law described in http://www.legifrance.gouv.fr/affichTexte.do it is the government that designates the physicians, who are able to intervene in a procedure of legal medical expertise (after some suspected medical errors). So they are supposed to have the skills and abilities for problems solving of complex medical errors with appropriate measures. The practitioners involved in the telemedicine activities have made some agreements for adherence to operational conditional of remote practice of medicine. When there are many important differences between the practices and the national recommendations, some deep analyses are made in order to identify the root causes, better understand the organisational constraints and improving the level of adherence of practitioners.

This error identification based on the generated report and the acceptable arguments obtained after applying argumentative logic consists of classifying the discovered errors by using the MetaMap software, Makeham's taxonomy (that includes medical errors concepts) and Tempos taxonomy (that mentions the chronological sequences of errors).

At the beginning the expert report is injected in the online MetaMap software. The output or emerged concepts is matched with the ones in the taxonomies of Makeham (that includes medical errors concepts) and Tempos (that mentions the chronological sequences of errors). This matching facilitates the identification of relevant errors that occurred in the teleexpertise process.

We suppose that the following text in italic is a part of the report (see Fig. 4) produced by the experts after their expertise.

The tribunal (committee of experts) noted a diagnostic error resulting from a common fault at the Hospital Centre and at the University Hospital Centre, thereby engaging the joint and several liability of the two hospital establishments. This judgment indicates that the computed tomographic scan performed showed a major central cerebral herniation with the beginning of a temporal herniation, indicating that this very important radiological sign, which meant that the subdural haematoma, despite its apparent good clinical tolerance, was a severe form already threatening the patient by an aggravation leading to coma, was ignored by doctors who evaluated medical images in both establishments. The court considers on the remarks that if the university hospital raises a doubt about the reception of the two sets of pictures by his neurosurgery department and a question about the quality of images, there is no indication of anything in the report that physicians whom have received and interpreted the images have made some reservations about their quality and completeness.

\subsection{The different steps in case of litigation}

This section explicitly shows the different steps to follow in case of litigation according the proposed architecture (see Fig. 4). As previously said, when a litigation occurred a group of experts is formed. This group consists of medical professionals and courts' experts (Rougé, 2012). These experts analyse the generated report and the acceptable arguments in order to generate their own report that will be used by a judge to identify the errors that lead to the litigation. As a result, these elements can shed light on the administrative and legal debates and it could be possible to know whether these errors could have been avoidable or not.

\subsubsection{Injection of the expert's report into MetaMap}

MetaMap (http://metamap.nlm.nih.gov) is a tool for recognising UMLS $^{1}$ (http://www.nlm.nih.gov/research/umls/) concepts in a text, but in UMLS there is no terminology that handles medical errors (Sangster and Patrick, 2002). However, Boxwala et al. (2003) tried to overcome this failure by proposing a terminology for medical errors that will make it possible to code patient safety and risk management (Boxwala et al., 2003). It is against this backdrop that the MetaMap as a means to map medical errors concepts including those from UMLS sources has been incorporated in the proposed tool in this study. In fact, MetaMap delivers configurable procedures for indexing medical documents and information retrieval. That is why it has been possible to adapt it for medical errors identification by semantic concepts mapping.

In order to deliver a correct annotation for a concept, the need of accurately engendering semantic context for concepts is considered. Clear and succinct information of a concept is important to specify its semantics and unseen meanings. The suggested method can consistently engender the context of a concept by using some prior knowledge such as taxonomic knowledge or the principles that underpins a hierarchical classification of used concepts. Generally, a semantic context of a concept consists of a set of structured associated information including semantically related concepts, context sentences, and temporal annotations (Xu et al., 2014).

Immediately after the injection of the expertise's report into the MetaMap online software, a screenshot of the output is shown in Fig. 8:

This screenshot shows that the first problem that leads to the litigation can be investigated in the Diagnostic Procedure as illustrated in red rectangles.

The errors identification follows a rigorous process. In fact after the consultation of the experts the generated report called "expert report" will be injected into the online MetaMap software in order to identify the involved concepts according to the UMLS. Hence, Fig. 8 shows the identification of the main errors concepts but not the mapping of the errors. After this step, the identified concepts will be used then for errors mapping by using the Makeham's taxonomy. In the expert report, it is said that there was ignorance from the medical professionals in the process of teleexpertise (which one leads to the litigation) about the analysis of the CT scan that showed a "very important radiological sign". Given that, there was a medical error, the MetaMap software made it possible to identify the main concept of Diagnostic procedure, and sub-concepts including radiology that uses imaging procedure for

\footnotetext{
${ }^{1}$ Unified Medical Language System.
} 


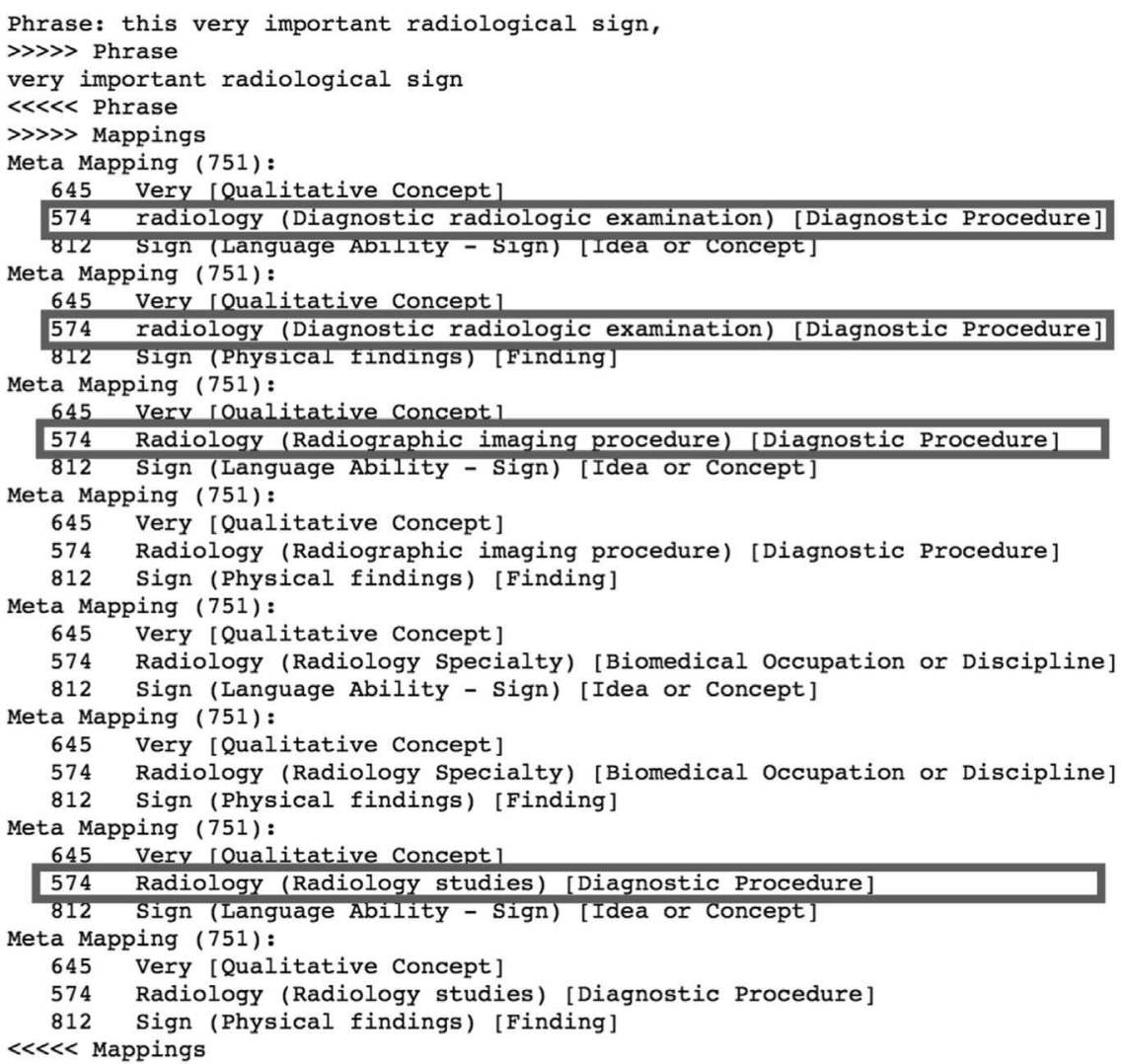

Fig. 8. Screenshot 1 of MetaMap output. (For interpretation of the references to color in this figure caption, the reader is referred to the web version of this paper.)

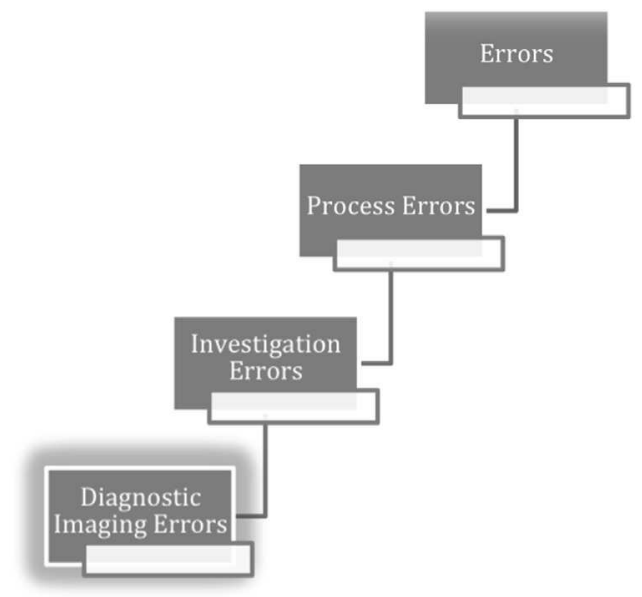

Fig. 9. Investigation errors identified according to Makeham's taxonomy

diagnosis. Then these key concepts are used for medical errors concepts mapping in the Makeham's taxonomy. The Diagnostic procedure maps with the concept Process errors in the Makeham's taxonomy and the terms radiology and imaging map with the concept Diagnostic imaging errors. This led to the conclusion that the relevant error is a Diagnostic imaging type.

\subsubsection{Errors identification according to Makeham's taxonomy}

Taking into consideration the concepts Diagnostic procedure and Radiographic imaging procedure, it is possible to find the path of errors in the Makeham's taxonomy. The path to the identified errors is depicted in Fig. 9.

After this step, it can be established the identified errors are Diagnostic Imaging Errors. So by referring to the text above an instantiation of these errors in this case is "Ignorance of very important radiological signs".

As it was an act of teleexpertise between a hospital and a university hospital, it is important to investigate if there was not an error of communication (Linkin et al., 2007) between these two institutions. That is why the effort or goal is to bring out this kind of error in the process of errors identification. It is already known that there was a communication between the hospitals since there was act of teleexpertise between them (refer to Scenario of teleexpertise 5.1.1). Consequently, by identifying this kind of error, will serve as basis for a deep investigation to be undertaken by the court in determining if a communication error actually occurred. The communication between the two hospitals is also illustrated in the expert report. As we have previously indicated, the concept Health Care Related Organization is highlighted in the red rectangles presented in Fig. 10.

After this step, the identified errors are depicted in Fig. 11, namely Errors in communication among the whole healthcare team.

An instantiation of these errors is The court considers on the remarks that if the university hospital "raises a doubt about the reception of two sets of pictures by his neurosurgery department and a questioning about the quality of images, there is no indication of anything in the report that physicians who have received and interpreted the images have made reservations about their quality and completeness, nor that they suggested to complete them".

After these steps, we can conclude this section with two major errors found, namely:

- Diagnostic Imaging Errors;

- Errors in communication among the whole healthcare team.

\subsubsection{Taking into account the Tempos taxonomy}

The Tempos' classification has been used in France since many years, but it is becoming at the international level as an analysis method taking better account of the patient pathway. In addition, 


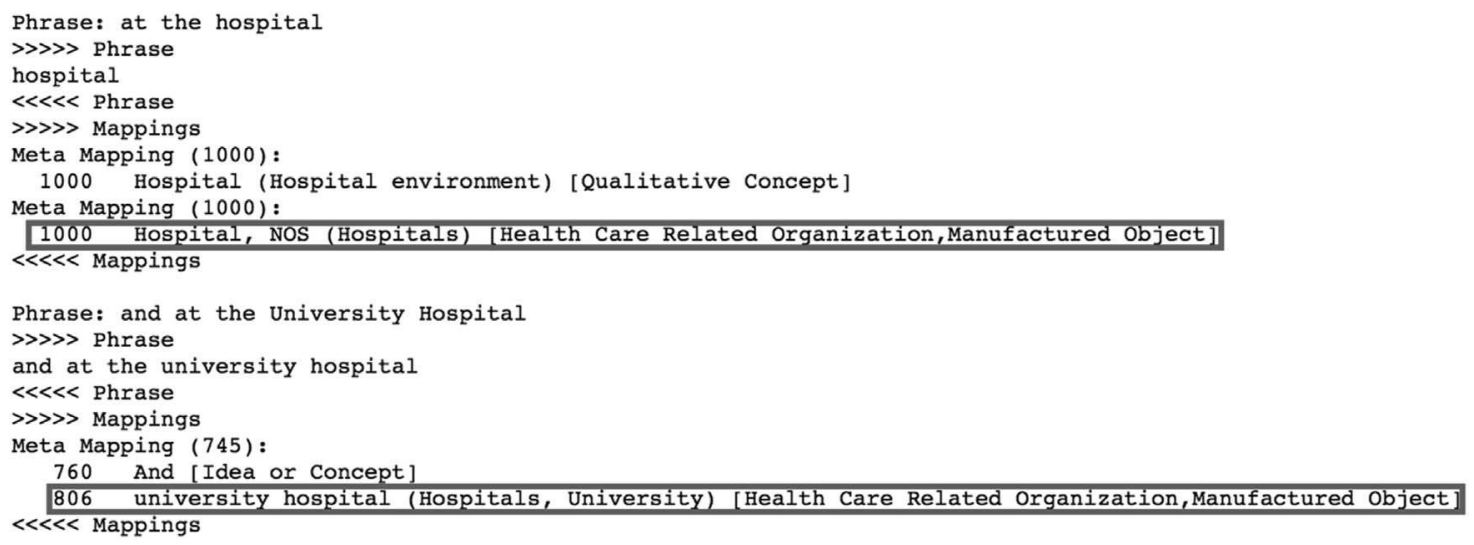

Fig. 10. Screenshot 2 of MetaMap output. (For interpretation of the references to color in this figure caption, the reader is referred to the web version of this paper.)

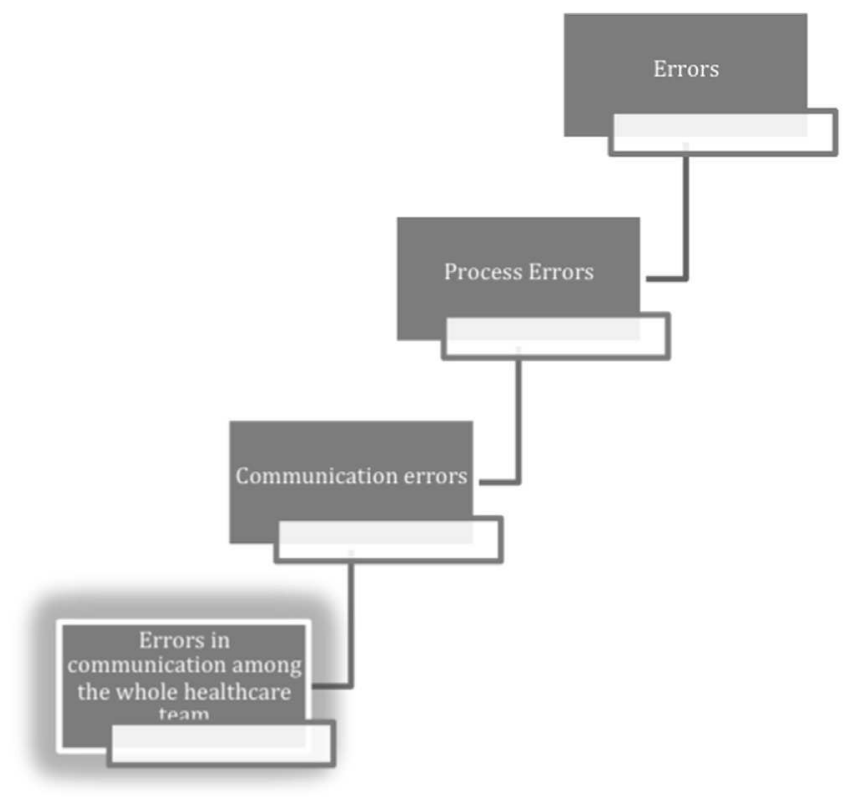

Fig. 11. Communication errors identified according to Makeham's taxonomy.

this classification takes into consideration the general constraints of the medical practice by emphasising the temporal dimensions of medical activities in which errors arise mainly from the procedures coordination and consistency and incomplete guidelines (http://www.invs.sante.fr/beh/2014/24-25/pdf/2014_24-25.pdf).

In our case, the identified Tempos are listed below:

- Disease tempo: A patient is admitted in a Hospital Centre due to a head injury after a paragliding accident. A computed tomography (CT) of human brain was performed, but since it showed no abnormalities, the patient was allowed to leave the hospital a few days later. A month later, this patient was hospitalised again due to an unusual headache unimproved by with analgesics and vomiting. CT scan was performed and a teleexpertise has been requested to neurosurgery department of a University Hospital Centre with video transmission of images resulting from an examination that shows a bilateral frontalparietal subdural haematoma.

- Out-office coordination/referral tempo: No report transmission between the two establishments.

- Access to knowledge: The physicians of the university hospital decided to postpone the intervention due to aspirin, and then the patient fell into a coma and passed away shortly after.

\subsubsection{Identified errors, classification and verification}

The previous steps permit to identify the occurred errors that lead to the litigation. According to the Makeham's taxonomy and the Tempos taxonomy these errors are classified into three categories, which represent types of risk situations (http://www.invs. sante.fr/beh/2014/24-25/pdf/2014_24-25.pdf):

- Knowledge and skill mobilisation;

- Writing prescriptions (computerised or not);

- Organisation of work within the structures in primary cares.

The last step consists of verifying if these potential risk situations was avoidable or not in order to identify the root causes and to place the responsibilities or to suggest the applicable corrective measures and preventive actions. This step is done manually by the medical and legal experts, but we are investigating on how to automatise it in future work. The ending process will permit to know the responsibilities involved in damaging consequences for patients by distinguishing the therapeutic contingency and the medical fault (direct or indirect causality). The medical liability is determined exclusively in the light of an analysis of each patient's medical circumstances with deontological and safety considerations.

To summarise, the errors are identified through a matching between concepts included in the expert report and taxonomies such as Makeham's taxonomy and Tempos taxonomy. The Makeham's taxonomy is used in several medical studies in the world, while the Tempos taxonomy is very used in France over the last few years. For the validation related to the identification of errors there is a consultation between the legal experts to provide a comprehensive assessment report. The legal experts are medical professional established by Article L. 1142-10 of the French Public Health Code (http://www.legifrance.gouv.fr/affichTexte.do). The national list of legal experts serves as reference for appointing expert medical professionals in a context of the litigation. The medical professionals (categorised by discipline) are accredited to be included on this list on the basis of their respective qualifications and practical experience. These ones are considered to have the necessary skills and competencies to reach a consensus and deliver the final results about the validation of the identified errors.

\section{Discussion}

The rationale for this study has been the need or zeal to assist medical and legal experts in investigations when a litigation occurred in the practice of tele-expertise. In this work, a model 
based on Dung's argumentation system (Dung, 1995) was developed. The Dung's argumentation system is based on mathematical foundations and taxonomic knowledge. It is important to note that there is paucity of peer-reviewed literature about studies that have extended the Dung's argumentative framework for decisionmaking in teleexpertise. The few studies have been related to decision making process in crisis environment. For example Cesta et al. (2014) proposed a system called PANDORA which is based on Artificial Intelligence that facilitates decision makers' training in crisis environment. We were inspired by this approach and proposed ours for teleexpertise especially in circumstances where vulnerable patients require urgent treatment remotely. It can be noted that by the approach in Cesta et al. (2014) some of their solutions are simulated in a training environment. The natural question is that of knowing whether these solutions are reliable assessments? To overcome this ambiguity, in our approach the solutions are provided by medical professional accompanied with sources of arguments and stored into servers. Based on our previous work (Doumbouya et al., 2015a,c), we have added another concept called sources, which will allow medical professionals to inform where they took their information in the decision making process. So when a litigation occurs, these sources will be processed to know if they are reliable or not. Moreover, this work can be used to prevent crisis situation since it can be as a learning tool for initiatives including experience feedback processes. Also, the MetaMap software is not a real time, as some text can take hours to be processed (Aronson and Lang, 2010), which means that some improvements have to be realised to overcome this failure.

The proposed work positions itself as a tool used in a posteriori analysis of teleexpertise in order to provide legal expertises with improved information for litigation resolution procedures. The collected advices are stored into databases handle by a secure and evolutive information infrastructure. So these advices can be retrieved later to build specific knowledge bases according to the needs. The ICD-10 (International Classification of Diseases) is a kind of international medical knowledge base that helps medical professionals to their knowledge acquiring. It can be included in our knowledge base as medical concepts. The knowledge is drawn from the PMR and medical concepts such as UMLS and ICD-10, which is commonly used by medical practitioners. The PMR is well documented by the medical professionals and there is an algorithm to extract the necessary data for building the medical report and the argumentative logic. The argumentation system helps here to compute the potential acceptable arguments (advices) given by the different medical professionals in the act of teleexpertise. The details about the argumentation system are well explained in our previous work (Doumbouya et al., 2015a) it is why we do not find the need to explain it deeply in this work. To summarise, it is based on mathematical definitions and properties proposed by Dung, which permit to bring out the acceptable arguments according to a given semantics.

\section{Conclusions}

At the end of this study, it appears clearly that most litigations are due to medical errors. Many studies are being conducted to understand how to reduce or even eradicate these medical errors. In this study we have extended the use of Artificial Intelligence tools such as Dung's argumentation system in the goal of extracting and computing accepted decisions in the process of teleexpertise in which the litigation occurred. These extracted decisions helped to identify the committed errors via MetaMap software, the Makeham's and Tempos taxonomies.

The practical contribution of this study is two-fold. Firstly, the study is very useful for medical and legal experts as it facilitates their tasks to make good judgement in teleexpertise processes. Secondly, the proposed tool and the same occasion permit them to prevent risk due to generated knowledge since the provided means can be used for organisational learning with a perspective to continuous improvement.

The strength of the proposed tool lies in its ability to provide an opportunity to classify the detected errors according to the Makeham's and Tempos taxonomies and it is possible to highlight the preventable errors with possible severe consequences for the patients (dysfunction, disability or death). As part of future works, we will focus on the automation of some procedures of errors detection processes along with semantic association analysis computerisation.

\section{Acknowledgements}

The authors are grateful to Dr Fonbeyin Henry Abanda (Oxford Brookes University) for his proofreading and editing service. We also thank some anonymous reviewers for their helpful feedback and observations on previous version of the paper.

\section{References}

Amalberti, R., Brami, J., 2012. 'Tempos' management in primary care: a key factor for classifying adverse events, and improving quality and safety. BMJ Qual Saf 21, 729-736. http://dx.doi.org/10.1136/bmjqs.2010.048710.

Aronson, Alan R., Lang, Francois-Michel, 2010. An overview of metamap: historical perspective and recent advances. J. Am. Med. Inform. Assoc. 17 (January (3)), 229-236.

Baget, J.F., Mugnier, M.L., 2002. Extensions of simple conceptual graphs: the complexity of rules and constraints. Journal of Artificial Intelligence Research (JAIR) $16,425-465$.

Bench-Capon, Trevor J.M., 2003. Persuasion in practical argument using valuebased argumentation frameworks. J. Log. Comput. 13 (January (3)), 429-448.

Besnard, P., Garcia, A., Hunter, A., Modgil, S., Prakken, H., Simari, G., Toni, F., 2014. Introduction to structured argumentation. Argum. Comput. 5, 1-4.

Baroni, Pietro, Giacomin, Massimiliano, 2009. Semantics of abstract argument systems. In: Simari, Guillermo, Rahwan, Iyad (Eds.), Argumentation in Artificial Intelligence. Springer, US, pp. 25-44.

Bourguet, Jean-Rémi, 2011. Contribution aux méthodes d'argumentation pour la prise de décision. Application à l'arbitrage au sein de la filière céréalière. Ph.D. Thesis, University of Montpellier.

Boxwala, Aziz A., Zeng, Qing T., Chamberas, Anthony, Sato, Luke, Dierks, Meghan, 2003. Coverage of patient safety terms in the UMLS metathesaurus. AMIA Annual Symposium proceedings/AMIA Symposium, pp. 110-114.

Bullock, M. Ross, Chesnut, Randall, Ghajar, Jamshid, Gordon, David, Hartl, Roger, Newell, David W., Servadei, Franco, Walters, Beverly C., Wilberger, Jack E., Surgical Management of Traumatic Brain Injury Author Group, 2006. Surgical management of acute subdural hematomas. Neurosurgery, 58 (March (3 Suppl)), S16-24; discussion Si-iv.

Cesta, Amedeo, Cortellessa, Gabriella, De Benedictis, Riccardo, 2014. Training for crisis decision making-an approach based on plan adaptation. Knowl.-Based Syst. 58 (march), 98-112.

Chalumeau, M., Dubos, F., Leroy, S., Moulin, F., Gendrel, D., Bréart, G., 2008. Quand et comment développer une règle de décision clinique aux urgences pédiatriques? Arch. de Pédiatr., 718-720.

Chavanon, O., Durand, M., Romain-Sorin, V., Noirclerc, M., Cracowski, J.L., Protar, D., Abdennadher, M., Blin, D., 2002. Does the time between preoperative interruption of aspirin intake and operation influence postoperative blood loss and transfusion requirement in coronary artery bypass graft? Ann. Fr. d'Anesth. et de Réanim. 21 (June (6)), 458-463.

Chein, M., Mugnier, M.-L., 2009. Graph-Based Knowledge Representation: Computational Foundations of Conceptual Graphs. Series: Advanced Information and Knowledge Processing, 445. Springer, London, United Kingdom, Hardcover.

CoGui: a graph-based tool for building conceptual graphs. Available (On-line): $\langle$ http://www.lirmm.fr/cogui//.

Direction générale de l'offre de soins. Télémédecine et responsabilités juridiques engagées 〈http://www.sante.gouv.fr/IMG/pdf/Telemedecine_et_responsabil ites_juridiques_engagees.pdf $\rangle$, mai 2012.

Doumbouya, M.B., Kamsu-Foguem, B., Kenfack, H., Foguem, C., 2014. Telemedicine using mobile telecommunication: Towards syntactic interoperability in teleexpertise. Telematics and Informatics 31 (Issue 4), 648-659, November.

Doumbouya, M.B., Kamsu-Foguem, B., Kenfack, H., Foguem, C., 2015a. A framework for decision making on teleexpertise with traceability of the reasoning. IRBM 36 (1), 40-51. 
Doumbouya, M.B., Kamsu-Foguem, B., Kenfack, H., 2015b. Argumentation and graph properties. Information Processing and Management . http://dx.doi.org/ 10.1016/j.ipm.2015.08.003.

Doumbouya, M.B., Kamsu-Foguem, B., Kenfack, H., Foguem, C., 2015. Combining conceptual graphs and argumentation for aiding in the teleexpertise. Computers in Biology and Medicine. 63, 157-168 (August).

Dung, P.M., 1995. On the acceptability of arguments and its fundamental role in nonmonotonic reasoning, logic programming and n-person games. Artif. Intell. J. 77, 321-357.

Elkin, Peter L., Beuscart-Zephir, Marie-Catherine., Pelayo, Sylvia, Patel, Vimla, Nøhr, Christian, 2013. The usability-error ontology. Stud. Health Technol. Inform. 194, 91-96.

Esprit 2013: a french epidemiological survey on medical errors associated to primary care. Available (On-line): 〈http://www.invs.sante.fr/beh/2014/24-25/pdf/ 2014_24-25.pdf (Date of access 24.10.2014).

Extensible Markup Language (XML). Available (On-line): 〈http://www.w3.org/XML/ $\rangle$.

Ge, Xiaocheng, Rijo, Rui, Paige, Richard F., Kelly, Tim P., McDermid, John A., 2012. Introducing goal structuring notation to explain decisions in clinical practice. Proc. Technol. 5.

Gortzis, L.G., Nikiforidis, G., 2008. Tracing and cataloguing knowledge in an e-health cardiology environment. J. Biomed. Inform 41 (April (2)), 217-223.

International classification of diseases. Available (On-line): 〈http://www.who.int classifications/icd/en/ (Date of access 27.03.2015).

Kamsu-Foguem, B., Diallo, G., Foguem, C., 2013. Conceptual graph-based knowledge representation for supporting reasoning in African traditional medicine. Engineering Applications of Artificial Intelligence 26 (4), 1348-1365, April.

Kamsu-Foguem, B., 2012. Knowledge-based support in Non-Destructive Testing for health monitoring of aircraft structures. Advanced Engineering Informatics 26 (4), 859-869, October.

Kamsu-Foguem, B., Foguem, C., 2014a. Telemedicine and mobile health with integrative medicine in developing countries. Health Policy and Technology 3 (Issue 4), 264-271, December.

Kamsu-Foguem, B., Foguem, C., 2014b. Could Telemedicine Enhance Traditional Medicine Practices? European Research in Telemedicine / La Recherche Européenne en Télémédecine 3 (Issue 3), 117-123, September.

Kamsu-Foguem, B., 2014c. Systemic modeling in telemedicine. European Research in Telemedicine / La Recherche Européenne en Télémédecine 3 (Issue 2), 57-65, June.

Kamsu-Foguem, B., 2014d. Ontological view in telemedicine. European Research in Telemedicine / La Recherche Européenne en Télémédecine 3 (Issue 2), 67-76, June.

Kamsu-Foguem, B., Tchuenté-Foguem, G., Foguem, C., 2014e. Conceptual graph operations for formal visual reasoning in the medical domain. IRBM 35 , 262-270 (October (5)).

Kamsu-Foguem, B., Tchuenté-Foguem, G., Foguem, C., 2014f. Using conceptual graphs for clinical guidelines representation and knowledge visualizationInf. Syst. Front. 16 (4), 571-589.

Kamsu-Foguem, B., Tchuenté-Foguem, G., Foguem, C., 2014g. Verifying a medical protocol with temporal graphs: the case of a nosocomial disease. J. Crit. Care 29, 690-691 (August (4)).

Kamsu-Foguem, B., Tiako, P.F., Fotso, L.P., Foguem, C., 2015a. Modeling for effective collaboration in telemedicine. Telematics and Informatics 32 (Issue 4), 776-786, November.

Kamsu-Foguem, B., Tiako, P.F., Mutafungwa, E., Foguem, C., 2015b. Knowledgebased Modeling Applied to Synucleinopathies. European Geriatric Medicine 6 (Issue 4), 381-388, July.
Koivisto, T., Jääskeläinen, J.E., 2009. Chronic subdural haematoma-to drain or not to drain? Lancet 374 (9695), 1040-1041.

Lawson, Anton E., Daniel, Erno S., 2011. Inferences of clinical diagnostic reasoning and diagnostic error. J. Biomed. Inform.

Linkin, Darren R., Fishman, Neil O., Landis, J. Richard, Barton, Todd D., Gluckman, Steven, Kostman, Jay, Metlay, Joshua P., 2007. Effect of communication errors during calls to an antimicrobial stewardship program. Infect. Control Hosp. Epidemiol. 28 (December (12)), 1374-1381.

Liste nationale des experts en accidents médicaux instituée par l'article 1. 1142-10 du code de la santépublique. Available (On-line): 〈http://www.legifrance.gouv. fr/affichTexte.do;jsessionid = 74028C545EDFE79110FF8884836FD9FB.tpdjo17v_ 3? cidTex

te $=$ JORFTEXT000028194372\&dateTexte $=$ \&oldAction $=$ rechJO\&categorieLien $=\mathrm{id} \& \mathrm{idJO}=\mathrm{JORFCONT000028193880}$, novembre 2013 (Date of access 27.03.2015).

Makeham, Meredith A.B., County, Mary, Kidd, Michael R., Dovey, Susan M., 2002. An international taxonomy for errors in general practice: a pilot study. Med. J. Aust. 177 (2)

MetaMap: a tool for recognising UMLS concepts in text. Available (On-line): 〈http:// metamap.nlm.nih.gov>.

Modgil, Sanjay, Caminada, Martin, 2009. Proof theories and algorithms for abstract argumentation frameworks. In: Simari, Guillermo, Rahwan, Iyad (Eds.), Argumentation in Artificial Intelligence. Springer, US, pp. 105-129.

Perlemuter, Gabriel, Perlemuter, Léon, 2014. Guide de thérapeutique 2015. 8ème édition edition, juin.

Rougé, Camille, 2012. L'expertise médicale judiciaire ou menée dans le cadre d'une procédure devant les commissions régionales d'indemnisation des accidents médicaux. Méd. Droit 2013 (mai (120)), 93-95.

Sangster, W., Patrick, T., 2002. Talking about medical errors: the void in existing controlled terminologies. In: Proceedings of the AMIA Symposium.

Santarius, T., Kirkpatrick, P.J., Dharmendra, G., 2009. Use of drains versus no drains after burr-hole evacuation of chronic subdural haematoma: a randomised controlled trial. Lancet 374 (9695), 1067-1073.

Sene, A., Kamsu-Foguem, B., Rumeau, P., 2015. Telemedicine Framework using Casebased Reasoning with Evidences. Computer Methods and Programs in Biomedicine 121 (Issue 1), 21-35, August 2015

Sowa, J.F., 1984. Conceptual Structures: Information Processing in Mind and Machine. The Systems Programming Series (Hardcover). Addison-Wesley Longman Publishing Co., Inc., Boston, MA, USA 481 pp.

Sowa, J.F., 2000. Knowledge representation: logical, philosophical, and computational foundations. Brooks Cole Publishing Co, Pacific Grove, California (U.S.A), p. 608, ISBN 0-534-94965-7.

Texte réglementaire, loi $\mathrm{n}^{\circ} 2009-879$ du 21 juillet 2009 portant réforme de l'hôpital et relative aux patients, à la santé et aux territoires. Available (On-line): 〈http://www.legifrance.gouv.fr/〉, juill 2009 (Date of access 29.10.2014).

Tribunal administratif de grenoble, mai 2010. n○ 0600648 (Responsabilité - Hôpital - Télé-expertise)

UMLS: Unified Medical Language System. Available (On-line): 〈http://www.nlm.nih. gov/research/umls/>.

Xu, Zheng, Liu, Yunhuai, Mei, Lin, Hu, Chuanping, Chen, Lan, 2014. Generating temporal semantic context of concepts using web search engines. J. Netw. Comput. Appl. 43 (August), 42-55. 